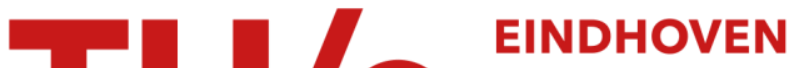 UNIVERSITY OF TECHNOLOGY
}

\section{Multivalent ultrasensitive interfacing of supramolecular 1D nanoplatforms}

Citation for published version (APA):

Magdalena Estirado, E., Aleman Garcia, M. A., Schill, J., \& Brunsveld, L. (2019). Multivalent ultrasensitive interfacing of supramolecular 1D nanoplatforms. Journal of the American Chemical Society, 141(45), 1803018037. https://doi.org/10.1021/jacs.9b05629

DOI:

10.1021/jacs.9b05629

Document status and date:

Published: 13/11/2019

\section{Document Version:}

Publisher's PDF, also known as Version of Record (includes final page, issue and volume numbers)

\section{Please check the document version of this publication:}

- A submitted manuscript is the version of the article upon submission and before peer-review. There can be important differences between the submitted version and the official published version of record. People interested in the research are advised to contact the author for the final version of the publication, or visit the $\mathrm{DOI}$ to the publisher's website.

- The final author version and the galley proof are versions of the publication after peer review.

- The final published version features the final layout of the paper including the volume, issue and page numbers.

Link to publication

\section{General rights}

Copyright and moral rights for the publications made accessible in the public portal are retained by the authors and/or other copyright owners and it is a condition of accessing publications that users recognise and abide by the legal requirements associated with these rights.

- Users may download and print one copy of any publication from the public portal for the purpose of private study or research.

- You may not further distribute the material or use it for any profit-making activity or commercial gain

- You may freely distribute the URL identifying the publication in the public portal.

If the publication is distributed under the terms of Article 25fa of the Dutch Copyright Act, indicated by the "Taverne" license above, please follow below link for the End User Agreement:

www.tue.nl/taverne

Take down policy

If you believe that this document breaches copyright please contact us at:

openaccess@tue.nl

providing details and we will investigate your claim. 


\title{
Multivalent Ultrasensitive Interfacing of Supramolecular 1D Nanoplatforms
}

\author{
Eva Magdalena Estirado, ${ }^{\dagger}$ Miguel Angel Aleman Garcia, ${ }^{\dagger}$ Jurgen Schill, and Luc Brunsveld*(0)
}

Laboratory of Chemical Biology, Department of Biomedical Engineering and Institute for Complex Molecular Systems, Eindhoven University of Technology, Den Dolech 2, 5612 AZ Eindhoven, The Netherlands

\section{Supporting Information}

\begin{abstract}
Multivalent display on linear platforms is used by many biomolecular systems to effectively interact with their corresponding binding partners in a dose-responsive and ultrasensitive manner appropriate to the biological system at hand. Synthetic supramolecular multivalent displays offer a matching approach for the modular and bottom-up construction and systematic study of dynamic 1D materials. Fundamental studies into multivalent interactions between such linear, 1D materials have been lacking because of the absence of appropriate modular nanoplatforms. In this work
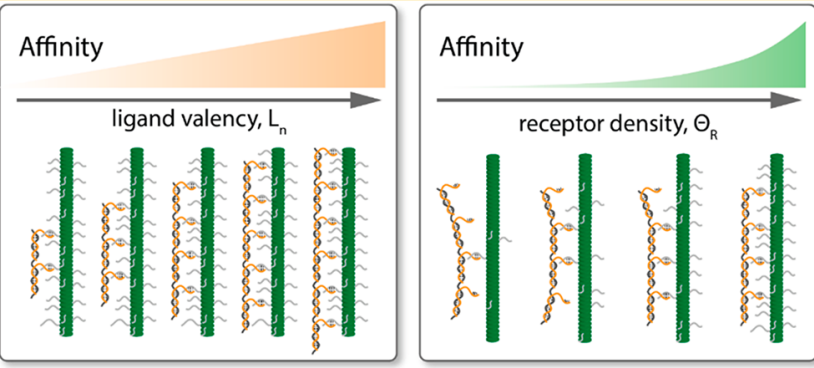
we interfaced two synthetic multivalent linear nanoplatforms based on a dynamic supramolecular polymer, formed by hybrid discotic-oligonucleotide monomers, and a series of complementary DNA-duplex-based multivalent ligands, also with appended short oligonucleotides. The combination of these two multivalent nanoplatforms provides for the first time entry to study multivalent effects in dynamic $1 \mathrm{D}$ systems, of relevance for the conceptual understanding of multivalency in biology and for the generation of novel multivalent biomaterials. Together the two nanoscaffolds provide easy access to libraries of multivalent ligands with tunable affinities. The DNA scaffold allows for exact control over valency and spatial ligand distribution, and the discotic supramolecular polymer allows for dynamic adaptation and control over receptor density. The interaction between the two nanoplatforms was studied as a function of ligand interaction strength, valency, and density. Usage of the enhancement parameter $\beta$ allowed quantification of the effects of ligand valency and affinity. The results reveal a generalized principle of additive binding increments. Receptor density is shown to be crucially and nonlinearly correlated to complex formation, leading to ultrasensitive responses. The results reveal that, not unlike biomolecular signaling, high density multivalent display of receptors is crucial for functionally increased affinities.
\end{abstract}

\section{INTRODUCTION}

Multivalency plays a critical role in tuning and increasing the affinity and selectivity between interaction partners in numerous biological systems. ${ }^{1-3}$ The combination of multiple interaction pairs allows for strong, yet dynamic, binding between platforms displaying the complementary binding partners, even when the individual interaction pairs bind only weakly. ${ }^{4,5}$ For instance, the clustering of receptors on the cell surface, due to the interaction with extracellular multivalent ligands, results in intracellular downstream signals that activate specific signaling pathways. ${ }^{6}$ Inside the cell, the activation of gene transcription typically occurs upon the joint oligomerization of multiple transcription factors on specific DNA sequences. The DNA acts as a quasi $1 \mathrm{D}$ platform for the templated assembly of multiprotein complexes, as a mechanism to overcome the low binding affinity of the individual proteins and to install selectivity in the gene regulation. ${ }^{7,8}$ Synthetic materials like polymers, 2D nanomaterials, and branched dendrimers have all been used as engineered multivalent platforms to enhance binding affinities. $^{9-18}$ In contrast to most biological multivalent systems, these synthetic materials are typically not of a supramolecular nature but of a polymeric or nanoparticle nature. As a result, systems studied thus far only have limited internal self-reorganization capacity to adapt to their complementary multivalent binding partners in a dynamic and potentially ultrasensitive manner, as observed for supramolecular biological systems. ${ }^{19,20}$

Synthetic supramolecular systems provide an alternative entry into multivalent nanoplatforms, with properties more aligned to their biological counterparts, including novel regulatory properties. ${ }^{21-24}$ The intrinsic dynamic nature of supramolecular systems facilitates rearrangement of interaction pairs within the multivalent platform, providing responsive and functional adaptation. It nevertheless remains a challenge to vary the ligand valency, position, and density in a controlled manner on such synthetic multivalent platforms, which limits exploration to the effects of these parameters on the interfacing of supramolecular nanoplatforms. While both 2D and 3D materials have received considerable conceptual evaluation regarding the effects and fundamentals of the multivalency

Received: May 26, 2019

Published: October 17, 2019 
a)

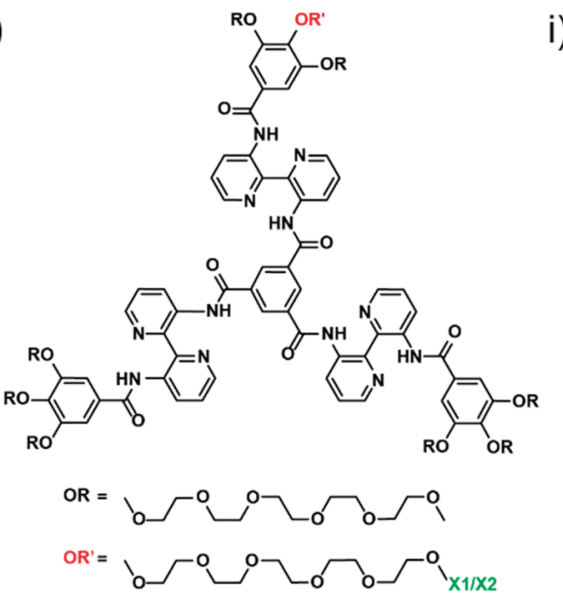

b)

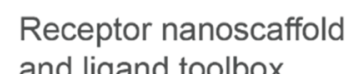
and ligand toolbox

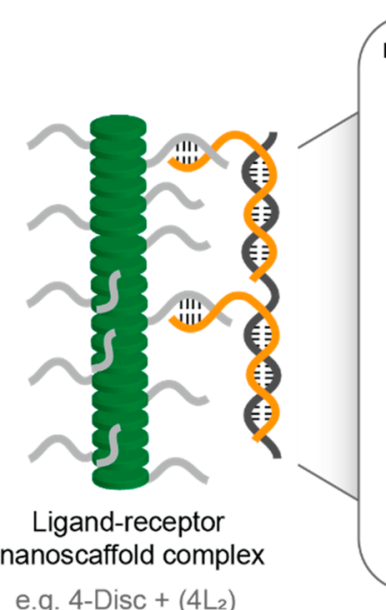

e.g. 4-Disc $+\left(4 L_{2}\right)$ i)
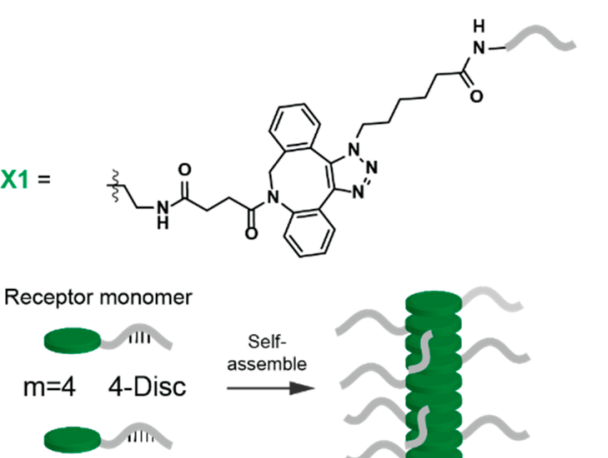

$m=5 \quad 5-$ Disc

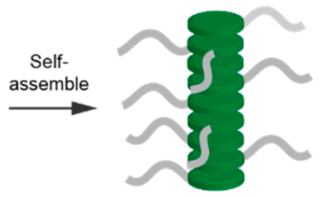

Receptor nanoscaffold ii)

$\mathrm{X} 2=\mathrm{Me}$

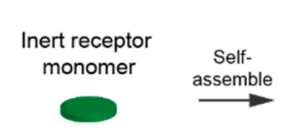

$\mathrm{m}=0 \quad$ Inert-Disc c) Oligonucleotide sequences

Series I: $m=4$

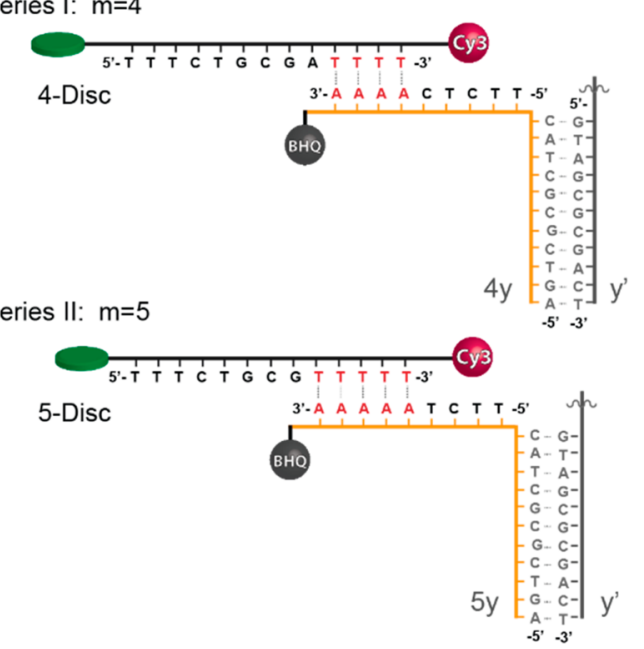

Figure 1. (a) Chemical structures of (i) DNA-overhang-functionalized receptor monomers (4-Disc and 5-Disc), where the DNA overhangs are shown as light gray curved lines on the green discotic scaffold, and (ii) unfunctionalized monomer (Inert-Disc). In water, the discotic monomers self-assemble into columnar stacks, referred to here as receptor nanoscaffold. (b) Schematic representation of the receptor-ligand complex formed by the receptor nanoscaffold (made out of the discotics) and the DNA-duplex-based ligands. The ligand $\left(m \mathrm{~L}_{n}\right)$ and its corresponding components are shown: in yellow the branches $(m \mathrm{x}$ and $m y)$ and in dark gray the backbones $\left(\mathrm{B}_{n}\right)$. " $n$ " denotes the valency of the ligands, while " $m$ " represents the number of complementary A-T base pairs between the DNA overhangs. The backbone units are made of sequences $x^{\prime}$ and $y^{\prime}$ which are complementary to the branches $m \mathrm{x}$ and $m \mathrm{y}$, respectively. The complementary base pairs between ligand/receptor and backbone/branches are drawn with black dashed lines. (c) Specific DNA sequences used for the DNA-functionalized discotic monomers (4-Disc and 5-Disc) and exemplary DNA-based ligands of series I $(m=4)$ and series II $(m=5)$. The DNA sequences of branches $4 \mathrm{x}$ and $5 \mathrm{x}$ are shown in Figure S2.

phenomenon, ${ }^{4,6}$ in contrast, linear 1D scaffolds have been addressed significantly less, ${ }^{22}$ especially within a context of biomolecular recognition. ${ }^{25}$

DNA is a molecular programmable material that can be used as nanoplatform with controlled positioning of bioactive ligands. ${ }^{26}$ Additionally, short DNA oligonucleotide overhangs can be used as modular interaction pairs with controllable interaction strength by varying the number and identity of complementary base pairs. ${ }^{27-29}$ Interfacing DNA materials with supramolecular materials has shown great promise in generating emergent properties. ${ }^{30-33} \mathrm{We}$ and others have previously reported on the synthesis and study of supramolecular polymers featuring appended DNA strands as ligands for inducing specific interactions on a supramolecular platform. ${ }^{33-38}$ Typically, the DNA-decorated supramolecular monomers self-assemble into nanoplatforms that present short single-stranded DNA overhangs, together effectively acting as a linear, 1D, multivalent scaffold (see Figure 1a). These self- assembling multivalent platforms provide ideal systems for studying fundamental concepts in multivalent interactions, such as the role of ligand affinity, valency, and density in interacting $1 \mathrm{D}$ nanoplatforms.

Here, we have interfaced 1D supramolecular columnar assemblies of discotics with the 1D columnar nanoscaffolds formed by DNA duplexes, via short DNA overhangs as biomolecular interaction pairs, resulting in two multivalent linear nanoplatforms with controllable and responsive display of ligands (Figure 1b). The decoration of these nanoscaffolds with short oligonucleotide sequences, acting as controllable biomolecular ligands, allowed us to address the long-standing desire to study the interplay and role of valency, density, and interaction strength in well-defined quasi $1 \mathrm{D}$ multivalent platforms. The number of complementary base pairs between the DNA overhangs was adjusted to tune the overall affinity of multivalent complex formation between both platforms. The role of receptor density in the multivalent binding process was 

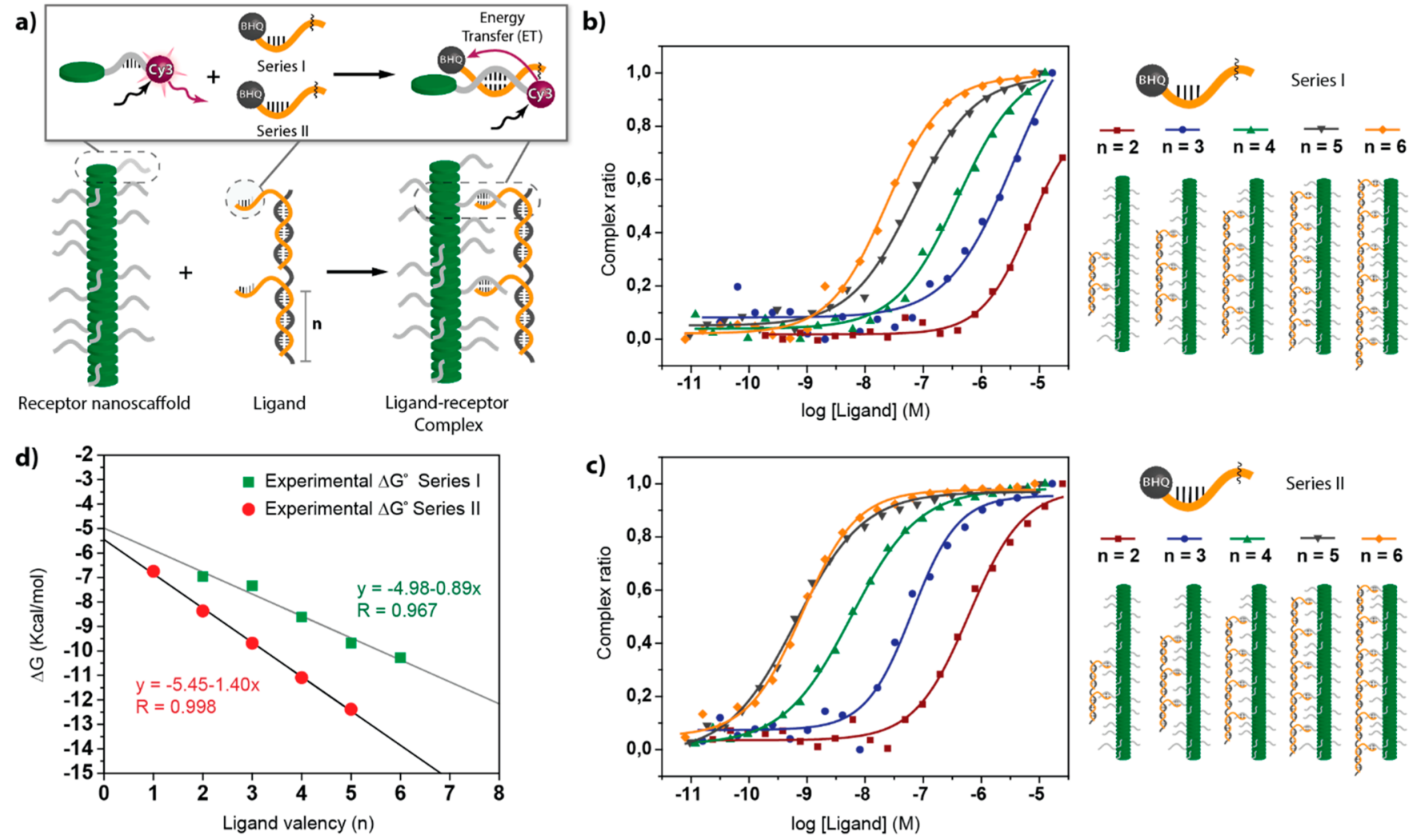

Figure 2. (a) Schematic representation of the Cy3-functionalized discotic receptor building block and nanoscaffold, and the BHQ-2-functionalized ligand nanoscaffold (series I and II respectively feature four and five bases of complementarity). Binding of the ligand to the receptor via duplex formation between the overhangs results in quenching of the Cy3-dye fluorescence. (b) Titration curves of series I ligands $\left(4 \mathrm{~L}_{2}, 4 \mathrm{~L}_{3}, 4 \mathrm{~L}_{4}, 4 \mathrm{~L}_{5}, 4 \mathrm{~L}_{6}\right)$ to the receptor nanoscaffold formed by the 4-Disc $(10 \mathrm{nM})$. (c) Titration curves of series II ligands $\left(5 \mathrm{~L}_{2}, 5 \mathrm{~L}_{3}, 5 \mathrm{~L}_{4}, 5 \mathrm{~L}_{5}, 5 \mathrm{~L}_{6}\right)$ to the receptor nanoscaffold formed by the 5-Disc $(10 \mathrm{nM})$. The assay concentration conditions limit the evaluation of binding affinities below $1 \mathrm{nM}\left(\right.$ see $5 \mathrm{~L}_{6}$, yellow line). (d) Gibbs free energies $\left(\Delta G^{\circ}\right)$ for each ligand-receptor complex formation plotted against the valency of the ligand $\left(\mathrm{L}_{n}\right)$ and linear fit for each series.

explored by systematically changing the composition of the supramolecular discotic polymer, revealing ultrasensitivity and providing insights into the nonlinear behavior of such adaptive supramolecular materials with biomolecular interaction pairs.

\section{RESULTS AND DISCUSSION}

Design of the Two Multivalent Nanoplatforms. Oligonucleotide-functionalized bis-pyridine-based $C_{3}$-symmetrical amphiphilic monomers ${ }^{39,40}$ were used as building blocks for the formation of the dynamic self-assembled receptor nanoscaffolds with single-stranded DNA overhangs ${ }^{35}$ (Figure 1a). Transmission electron microscopy shows the columnar assembly of these DNA-appended discotic monomers by virtue of the stacking of the discotics (Figure S1a), in line with observations on discotics decorated with other diverse functional groups. ${ }^{41}$ The resulting 1D assembly (termed "the receptor") can thus present multiple copies of single-stranded DNA overhangs. The receptor monomer toolbox consists of a discotic monomer featuring only glycol side-chains (InertDisc) and a set of single-stranded oligonucleotide-functionalized monomers (receptor monomer, $m$-Disc), with " $m$ " being the number of deoxythymidylates (4 or 5) available for hybridization. We selected these low numbers of complementary bases in the oligonucleotide overhangs to ensure binding via multivalent mechanisms only.

The multivalent DNA duplex-based nanoplatforms (termed "the ligand") were obtained by the assembly of a series of DNA branches ( $m \mathrm{x}$ and $m y$, Figure $1 \mathrm{~b})$ on single-stranded DNA backbones of different lengths. The repetition of the backbone units $\left(B_{n}\right)$ defines the final valency of the nanoscaffold ligands. The final assembly outcome is a double-stranded DNA duplex with " $n$ " number of single-stranded oligonucleotide overhangs with " $m$ " number of deoxyadenylates ( 4 or 5), complementary to the receptor oligonucleotide overhangs. The design accounts for the helicity of DNA-duplexes of 10.5 bases per turn to position the oligonucleotides at one side of the double helix (see Figure S2 for full details). The branches were designed with sequences $x$ and $y$ with 10 and 11 complementary bases of the respective DNA backbone repeating units $x^{\prime}$ and $y^{\prime}$. As depicted in Figure 1c, the overhangs of the ligand oligonucleotides are functionalized at the $3^{\prime}$-end with a quencher (BHQ-2), while the receptor oligonucleotides have a Cy3-dye at their 3 '-end. These two moieties allow us to monitor the duplex formation using FRET quenching; in the bound state, dye and quencher are in the required close proximity to observe fluorescence energy transfer with resulting quenching of the Cy3-fluorescence (see also Figure 2a).

Effect of Ligand Affinity and Valency. Ligand valency plays a key role in the enhancement of the binding affinities between ligands and receptors. Therefore, the effect of valency on the binding affinities between the two nanoplatforms was tested using a library of ligands (Figure 2). The experiments were carried out for two series of ligands with four (series I, 
$4 \mathrm{~L}_{n}$ ) and five (series II, $5 \mathrm{~L}_{n}$ ) complementary base pairs to the discotic receptor nanoscaffold (built up out of 4-Disc or 5Disc, respectively). Agarose gel was first used to confirm the integrity of the DNA-based ligand assemblies. Singular bands correlated to a gradual decrease in electrophoretic mobility with increasing ligand valency $(n)$ and could clearly be distinguished (Figure S4).

The binding studies between the supramolecular receptor and the DNA duplex ligand series were followed using the quenching of the fluorescence of the Cy3-labeled receptor as a reporter to determine the fraction of bound receptor.

First, the formation of the ligand-receptor complex was followed over time (see Figure S5). Upon addition of the quencher-labeled ligand, an immediate drop in the Cy3-dye fluorescence signal at $570 \mathrm{~nm}$ was observed. The fluorescence spectra did not change over the course of $15 \mathrm{~min}$, revealing fast kinetics for the ligand-receptor complex formation. Potential background binding or unspecific fluorescence quenching by the ligands was evaluated by titrating a tetravalent ligand with mismatching DNA sequence to the receptor nanoscaffold. At concentrations only in the high micromolar regime, the titration curve (see Figure S6) showed background fluorescence quenching of the Cy3-dye, due to the high concentration of quencher in solution, confirming absence of aspecific interactions between the two $1 \mathrm{D}$ nanoscaffolds. Transmission electron microscopy (Figure S1b,c) and temperature-dependent spectroscopic optical studies (Figure S7) confirmed the assembly of the discotics into the typical columnar nanoscaffolds, also upon binding of the DNA-based ligands.

Figure $2 b$ and Figure $2 c$ depict the binding isotherms for both series I and series II, respectively. The association constants for the corresponding series are calculated from the titration curves (Table 1). The increase in valency of the ligands for both series shows a linear correlation with the overall association constants (Figure $2 \mathrm{~d}$ ). As expected, series II, made of ligands with five complementary bases, has overall higher association constants than series I, which only uses four complementary bases. As a result of the higher monovalent

Table 1. Association Constants $\left(K_{\mathrm{a}}\right)$, Free Energies $\left(\Delta G^{\circ}\right)$, and the $\beta$ Enhancement Factor of the Ligand Series $I$ and Series II

\begin{tabular}{cllll}
\hline & \multicolumn{1}{c}{ ligand $\left(\mathrm{L}_{n}\right)$} & \multicolumn{1}{c}{$\Delta \mathrm{G}^{\circ}$} & \\
series I & $4 \mathrm{~L}_{1}$ to free & $1.32 \times 10^{3 a}$ & $-4.2^{a}$ & \\
& $\mathrm{DNA}^{b}$ & & & \\
& $4 \mathrm{~L}_{2}$ & $1.10 \times 10^{5}$ & -6.7 & $8.2 \times 10^{1}$ \\
& $4 \mathrm{~L}_{3}$ & $2.79 \times 10^{5}$ & -7.3 & $2.1 \times 10^{2}$ \\
& $4 \mathrm{~L}_{4}$ & $2.53 \times 10^{6}$ & -8.6 & $1.9 \times 10^{3}$ \\
& $4 \mathrm{~L}_{5}$ & $1.54 \times 10^{7}$ & -9.7 & $1.2 \times 10^{4}$ \\
& $4 \mathrm{~L}_{6}$ & $4.31 \times 10^{7}$ & -10.3 & $3.3 \times 10^{4}$ \\
series II & $5 \mathrm{~L}_{1}$ to free & $1.50 \times 10^{4}$ & $-5.6^{a} /-5.7$ & \\
& $\mathrm{DNA}^{b}$ & & & \\
& $5 \mathrm{~L}_{1}$ & $1.07 \times 10^{5}$ & -6.8 & $1.1 \times 10^{2}$ \\
& $5 \mathrm{~L}_{2}$ & $1.64 \times 10^{6}$ & -8.4 & $1.0 \times 10^{3}$ \\
& $5 \mathrm{~L}_{3}$ & $1.56 \times 10^{7}$ & -9.7 & $1.2 \times 10^{4}$ \\
& $5 \mathrm{~L}_{4}$ & $1.75 \times 10^{8}$ & -11.1 & $1.1 \times 10^{5}$ \\
& $5 \mathrm{~L}_{5}$ & $1.59 \times 10^{9}$ & -12.4 & $\mathrm{nd}$
\end{tabular}

${ }^{a}$ Calculated value. ${ }^{b}$ Affinity of the DNA overhang when not displayed on the receptor. ${ }^{c}$ nd: not determined. binding affinity within series II, only two ligands $\left(5 \mathrm{~L}_{2}\right)$ are required to observe full binding between the two nanoplatforms at the concentrations studied. In contrast, for series I three $\left(4 \mathrm{~L}_{3}\right)$ receptor-ligand interactions just sufficed to observe complete binding saturation. The stronger monovalent binding affinity within series II results in the hexameric $(n=6)$ ligand having a binding affinity which is beyond the assay window (Figure 2c, yellow line). The monovalent binding affinity for series I was too weak to be experimentally determined and was therefore only calculated (Table 1 ).

Figure $2 \mathrm{~d}$ shows the plotting of the change in free energy $\left(\Delta G^{\circ}\right)$ versus the ligand valency. The free energy values are extracted from the binding isotherms obtained in Figure $2 b$ and Figure $2 \mathrm{c}$. The results show a linear relationship between the number of binding epitopes $(n)$ and the free energy $\left(\Delta G^{\circ}\right)$ associated with the binding event for both series. The slope of the line represents the sensitivity of the system to changes in the number of epitopes. The slope of series I (with four complementary base pairs) has a value of -0.89 , while in series II (with five complementary base pairs) the slope value is -1.4 $\mathrm{kcal} / \mathrm{mol}$. This result indicates that the favorable energetic contribution of each additional binding epitope depends on the binding strength of the interaction between the ligand and the receptor.

Multivalent interactions are often characterized using the cooperativity factor $\alpha$ or the effective molarity parameter (EM).$^{42-47}$ However, these parameters are not suitable for a dynamic supramolecular system, since the exact geometry, the statistical factors of all the possible interactions, and the stoichiometry of the interaction are not known and will responsively change upon adjustments to the system. Our supramolecular nanoscaffold receptor has an unknown and adaptive number of available epitopes for binding, with different interaction geometries. Hence, in order to quantify the role of the multivalency effect in our system, we strictly used the "enhancement parameter" $\beta$ as defined by Whitesides et al. ${ }^{5}$ The term $\beta$ (eq 1) quantifies the contribution of the multivalent interaction in relation to the monovalent interaction, in a simplified manner.

$$
\beta=\frac{K_{n}^{\text {multi }}}{K^{\text {mono }}}
$$

where $\beta$ is the enhancement parameter, $K_{n}^{\text {multi }}$ is the association constant of the $n$-valent interaction, and $K^{\text {mono }}$ is the association constant of the monovalent interaction. The parameter $\beta$ was calculated for both series (I and II) using the theoretically expected $K^{\text {mono }}$. The expected monovalent association constant values were obtained using the NuPack package (see Figure S8). The monovalent interaction with four complementary bases has a $\Delta G^{\circ}$ value of $-4.2 \mathrm{kcal} / \mathrm{mol}$, and the corresponding system with five base pairs has a $\Delta G^{\circ}$ value of $-5.6 \mathrm{kcal} / \mathrm{mol}$. The theoretically expected $\Delta G^{\circ}$ value of the monovalent interaction for series II was also experimentally corroborated, giving a value of $-5.7 \mathrm{kcal} / \mathrm{mol}$ (Figure S9a). The enhancement parameter $\beta$ (Table 1, Figure S10) shows that series II is more sensitive to the increase of valency $(n)$ than series I. Since the contribution of each individual binding epitope is lower in series I than in series II, the increase in the number of interactions is reflected in higher $\beta$ values for series II.

It is worth noticing that the theoretical values of the monovalent base pairing of the overhangs do not correspond 
a)

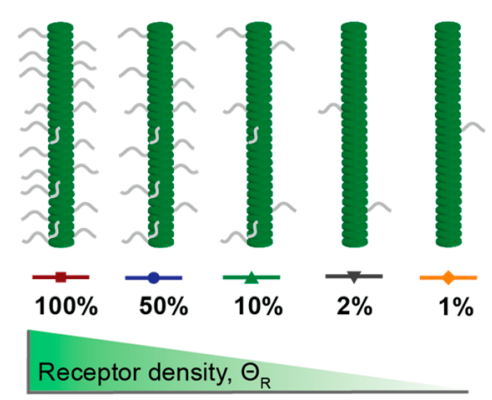

d)

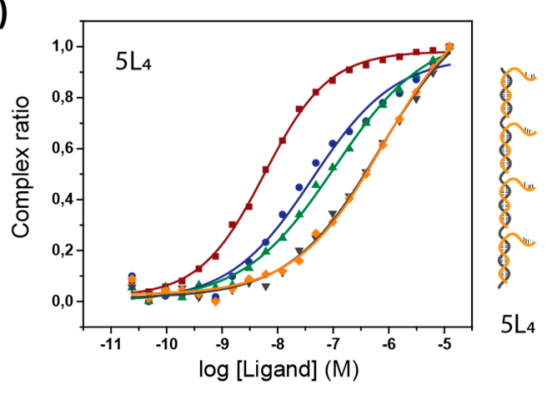

b)

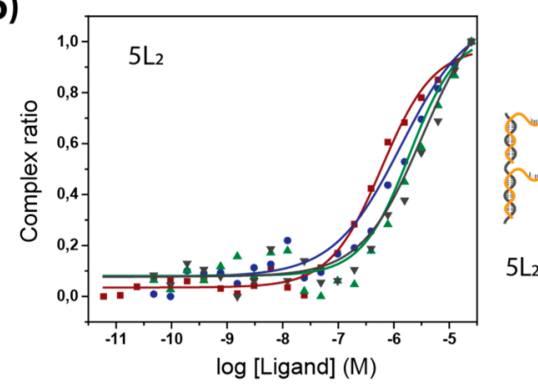

e)

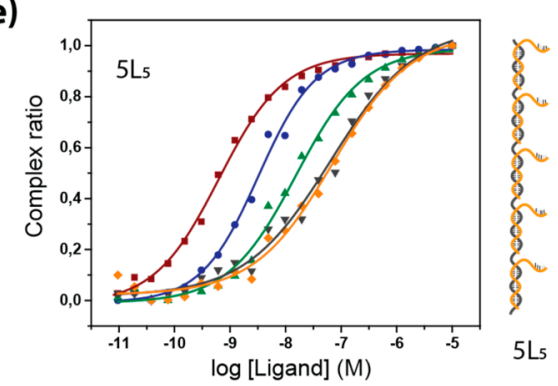

c)

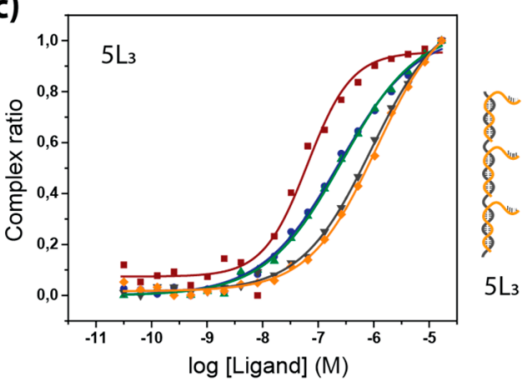

f)

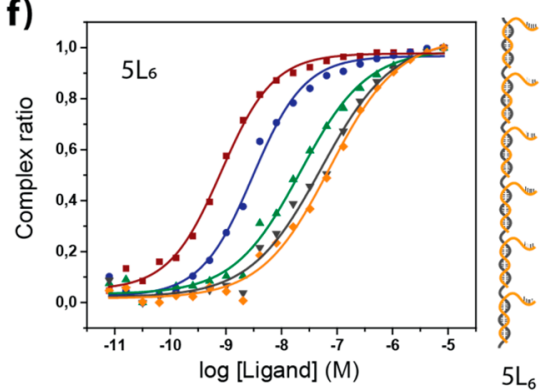

g)

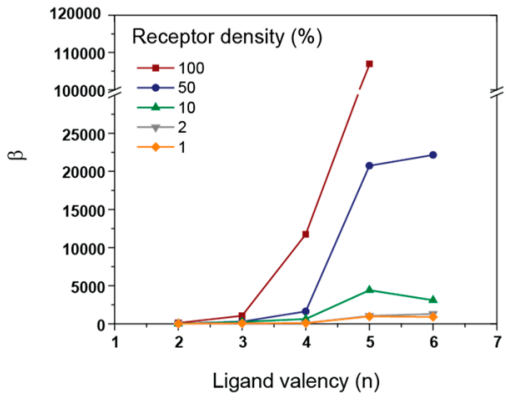

h)

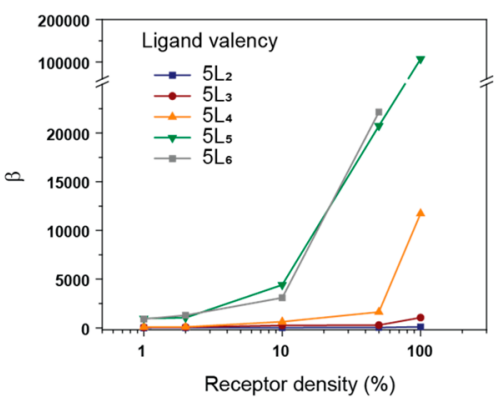

Figure 3. (a) Schematic representation of receptor nanoscaffold with different densities of DNA overhangs. Note that the total concentration of receptor buildings blocks with DNA overhangs (i.e., 5-Disc) was kept constant and that the density was controlled by the addition of Inert-Disc. $(\mathrm{b}-\mathrm{f})$ Titration curves of ligands $5 \mathrm{~L}_{2}-5 \mathrm{~L}_{6}$ from series II with five complementary base pairs to the receptor nanoscaffolds with differing receptor density (for color coding see (a)). The concentration of 5-Disc was constant at $10 \mathrm{nM}$. $\beta$ enhancement factors calculated with eq 1 (see also Table S3), plotted against $(\mathrm{g})$ the ligand valency $(n)$ and $(h)$ receptor density $\left(\Theta_{R}\right)$.

to the values that can be extracted from the fit of the data (Figure 2d, Table 1, Table S2). Thus, we measured the association constant for the case of the monovalent $5 \mathrm{~L}_{1}$ ligand with the receptor supramolecular nanoscaffold 5-Disc under adjusted assay conditions enabling us to measure this weaker affinity (Figure S9b). This monovalent binding affinity of the 5-Disc corresponded nicely to the fit from the plot in Figure $2 \mathrm{~d}$ (series II, $n=1$ ). It can thus be concluded that the display of the DNA overhangs on the supramolecular nanoscaffold translates into a higher monovalent association value due to the high, multivalent density of available receptor strands. When the supramolecular nanoscaffold is present, the rebinding of the dissociated ligands is more favorable due to the high ligand density making the dissociation of the ligand shift to the bound state. The energetic contribution of this multivalent display in the nanoscaffold to the binding affinity is $-1.1 \mathrm{kcal} / \mathrm{mol}$.

Effect of the Receptor Density. Next to enhancing interaction strengths, multivalency can also increase the sensitivity of the interaction between binding partners in a nonlinear manner. Among others, the binding strength can be sensitive to the receptor concentration, resulting in ultrasensitivity, ${ }^{19}$ potentially even superselectivity, ${ }^{22,48,49}$ but studies showing such events between two complementary linear supramolecular platforms have been lacking. We, therefore, explored the role of the receptor density on the interaction between these two $1 \mathrm{D}$ nanoscaffolds and probed its interplay with the valency of the ligands. For this, the receptor density $\Theta_{R}$ (eq 2) was varied by increasing the total number of monomers $\left(N_{\mathrm{T}}\right)$ via the additional incorporation of Inert-Disc (Figure 3a) at different ratios.

$$
\Theta_{\mathrm{R}}=\frac{N_{\mathrm{R}}}{N_{\mathrm{T}}} \times 100 \%
$$

The total concentration of receptor 5-Disc $\left(N_{R}\right)$ was thus kept constant $(10 \mathrm{nM})$, and the concentration of Inert-Disc monomers was varied from 0 to $1 \mu \mathrm{M}$, leading to nanoscaffolds with a receptor density $\Theta_{\mathrm{R}}$ ranging from $100 \%$ to $1 \%$. We selected series II for the receptor density studies because the higher epitope affinity for this series offers the study of a broader range of combinations of receptor densities and valencies.

The multivalent ligands of series II $\left(5 \mathrm{~L}_{n}\right)$ were incubated with the receptor platforms at the variable receptor densities. The binding isotherms of the $5 \mathrm{~L}_{2}-5 \mathrm{~L}_{6}$ ligands with the discotic nanoscaffolds of different receptor densities were 
monitored by using the quenching of the fluorescent signal of the receptor nanoscaffold upon binding of the quencherlabeled ligands. Figure 3 shows the binding curves corresponding to the multivalent ligands at different receptor densities $\Theta_{R}$ $(100,50,10,2,1 \%)$. The binding isotherms report a strong sensitivity of the affinity between the two nanoscaffolds on the receptor density. The values of the binding constants drop up to approximately 2 orders of magnitude upon reduction of receptor density but with constant receptor concentration. Table S3 reports the free energy $\left(\Delta G^{\circ}\right)$ values calculated for the ligand-receptor interactions at the different receptor densities. The lowering of the interaction strength is more pronounced with higher ligand valency; the $\Delta \Delta G$ between high and low receptor density is larger for the $5 \mathrm{~L}_{6}$ ligand than for the $5 \mathrm{~L}_{3}$ ligand for example (compare Figure $3 \mathrm{f}$ and Figure $3 \mathrm{c}$ and see Table S3). This phenomenon implies that for these ligand affinities the valency has a big effect in determining the binding event, requiring the supramolecular receptor scaffold to include multiple copies of the DNA overhangs in its structure. Reference studies with both nanoplatforms featuring DNA overhangs with significantly higher affinity, using seven and eight complementary base pairings, showed much less dependency on the receptor density in the concentration regime studied (Figure S11). In those cases, the strong ligand affinity thus overrules the need for precisely controlled valency numbers and density.

We also analyzed the receptor density binding affinities in terms of the enhancement parameter $\beta$ (Table S4, Figure $3 \mathrm{~g}, \mathrm{~h})$. The $\beta$ values converge to a lower limit for each multivalent ligand when the receptor density reached lower levels of around $2 \%$. Nevertheless, the $\beta$ values remained high, especially those of the ligands with higher valency, indicating that the number of multivalent interactions between the two nanoplatforms likewise remains high. The binding of the multivalent DNA nanoscaffold ligand to the discotic receptor platform thus probably plays a role in directing the templation of the supramolecular building blocks. Overall, the association constants for even the most dilute receptor densities measured are still significantly higher than those of the monovalent interaction. For instance, with the receptor diluted 100-fold $\left(\Theta_{\mathrm{R}}=1 \%\right)$, the association constant is still 3 orders of magnitude higher for the multivalent ligands $5 \mathrm{~L}_{6}$ and $5 \mathrm{~L}_{5}$ than that of the monovalent interaction. The steep, nonlinear rise in the $\beta$ values indicates ultrasensitivity of the interaction of the multivalent nanoplatforms for the receptor density. The interplay of ligand density, local concentration of receptors, dynamics within the supramolecular polymer and templated assembly of the discotics most probably all come to action to direct the overall assembly process and ultrasensitive response.

\section{CONCLUSIONS}

In this manuscript we bring forward the use of two $1 \mathrm{D}$ supramolecular nanoplatforms, based on a supramolecular polymer as receptor and on multivalent DNA-based ligands, to evaluate multivalent display on dynamic linear platforms. The sequential increase in the number of displayed DNA overhangs, as interacting elements between the two nanoplatforms, induces a linear increase in binding affinity, enhanced several orders of magnitude in comparison with the monovalent interaction. The DNA nanoplatform provides rapid access to a library of $1 \mathrm{D}$ multivalent ligands with tunable affinities, in both affinity and valency. The discotic supramolecular nanoplatform allows for simple tuning of ligand density by copolymerization with monomers without DNAoverhangs. The binding characteristics between both nanoplatforms were studied as a function of the ligand interaction strength, valency number, and ligand density. The effects of ligand valency and affinity of this multivalent system could be efficiently analyzed using the enhancement parameter $\beta$. The results reveal a generalized principle of additive binding increments, similar to the case of interactions between multivalent charged species, with a constant increment of $\Delta G=-1.4 \mathrm{kcal} / \mathrm{mol}$ per each additional ligand for series II. The receptor density was shown to be crucially and nonlinearly correlated with the binding affinities. A low display density of ligands was already leading to significant enhancements of the binding affinities in comparison to the monovalent binding affinity. An ultrasensitive increase in binding affinity was observed upon increased receptor densities, leading to strongly increased enhancement factors over a small range in receptor densities at constant receptor concentration.

The study of these synthetic multivalent double linear nanoplatforms provides for the first time entry to study multivalent effects in dynamic 1D systems, of relevance for the conceptual understanding of multivalency in biology and beyond and for the generation of novel ultrasensitive materials interfacing with biological matter. This molecular system might also open up opportunities to address outstanding questions in the field of supramolecular chemistry related to building block distribution within supramolecular assemblies and control over polymerization degree via multivalent templating.

\section{ASSOCIATED CONTENT}

\section{S Supporting Information}

The Supporting Information is available free of charge on the ACS Publications website at DOI: 10.1021/jacs.9b05629.

Experimental details, Tables S1-S4, and Figures S1S11 (PDF)

\section{AUTHOR INFORMATION}

\section{Corresponding Author}

*1.brunsveld@tue.nl

ORCID $\odot$

Luc Brunsveld: 0000-0001-5675-511X

\section{Author Contributions}

${ }^{\dagger}$ E.M.E. and M.A.A.G. contributed equally.

\section{Notes}

The authors declare no competing financial interest.

\section{ACKNOWLEDGMENTS}

We thank Pascal Pieters and Tom de Greef for useful discussions. The research described was funded by The Netherlands Organization for Scientific Research (NWO) through Gravity Program 024.001.035, VICI Grant 016.150.366, and through Marie Curie Independent Grant MSCA-IF-EF-ST SupramolecularWires and Marie Curie Innovative Training Network MULTI APP (2015-2019).

\section{REFERENCES}

(1) Li, P.; Banjade, S.; Cheng, H.-C.; Kim, S.; Chen, B.; Guo, L.; Llaguno, M.; Hollingsworth, J. V.; King, D. S.; Banani, S. F.; Russo, P. S.; Jiang, Q.-X.; Nixon, B. T.; Rosen, M. K. Phase Transitions in the Assembly of Multivalent Signalling Proteins. Nature 2012, 483, 336340. 
(2) Pawson, T. Assembly of Cell Regulatory Systems Through Protein Interaction Domains. Science 2003, 300, 445-452.

(3) Sriram, S. M.; Banerjee, R.; Kane, R. S.; Kwon, Y. T. Multivalency-Assisted Control of Intracellular Signaling Pathways: Application for Ubiquitin- Dependent N-End Rule Pathway. Chem. Biol. 2009, 16, 121-131.

(4) Fasting, C.; Schalley, C. A.; Weber, M.; Seitz, O.; Hecht, S.; Koksch, B.; Dernedde, J.; Graf, C.; Knapp, E.-W.; Haag, R. Multivalency as a Chemical Organization and Action Principle. Angew. Chem., Int. Ed. 2012, 51, 10472-10498.

(5) Mammen, M.; Choi, S.-K.; Whitesides, G. M. Polyvalent Interactions in Biological Systems: Implications for Design and Use of Multivalent Ligands and Inhibitors. Angew. Chem., Int. Ed. 1998, 37, 2754-2794.

(6) Multivalency: Concepts, Research \& Applications, 1st ed..; Huskens, J., Ed.; Wiley: Hoboken, NJ, 2018.

(7) Chen, H.; Privalsky, M. L. Cooperative Formation of HighOrder Oligomers by Retinoid X Receptors: An Unexpected Mode of DNA Recognition. Proc. Natl. Acad. Sci. U. S. A. 1995, 92, 422-426.

(8) Jolma, A.; Yin, Y.; Nitta, K. R.; Dave, K.; Popov, A.; Taipale, M.; Enge, M.; Kivioja, T.; Morgunova, E.; Taipale, J. DNA-Dependent Formation of Transcription Factor Pairs Alters Their Binding Specificity. Nature 2015, 527, 384-388.

(9) Mahon, E.; Barboiu, M. Synthetic Multivalency for Biological Applications. Org. Biomol. Chem. 2015, 13, 10590-10599.

(10) Rao, J.; Lahiri, J.; Weis, R. M.; Whitesides, G. M. Design, Synthesis, and Characterization of a High-Affinity Trivalent System Derived from Vancomycin and L -Lys- D -Ala- D -Ala. J. Am. Chem. Soc. 2000, 122, 2698-2710.

(11) Mulder, A.; Auletta, T.; Sartori, A.; Del Ciotto, S.; Casnati, A.; Ungaro, R.; Huskens, J.; Reinhoudt, D. N. Divalent Binding of a Bis(Adamantyl)-Functionalized Calix[4]Arene to $\beta$-CyclodextrinBased Hosts: An Experimental and Theoretical Study on Multivalent Binding in Solution and at Self-Assembled Monolayers. J. Am. Chem. Soc. 2004, 126, 6627-6636.

(12) Cecioni, S.; Imberty, A.; Vidal, S. Glycomimetics versus Multivalent Glycoconjugates for the Design of High Affinity Lectin Ligands. Chem. Rev. 2015, 115, 525-561.

(13) McRae, R. L.; Phillips, R. L.; Kim, I.-B.; Bunz, U. H. F.; Fahrni, C. J. Molecular Recognition Based on Low-Affinity Polyvalent Interactions: Selective Binding of a Carboxylated Polymer to Fibronectin Fibrils of Live Fibroblast Cells. J. Am. Chem. Soc. 2008, 130, 7851-7853.

(14) Conway, A.; Vazin, T.; Spelke, D. P.; Rode, N. A.; Healy, K. E.; Kane, R. S.; Schaffer, D. V. Multivalent Ligands Control Stem Cell Behaviour in Vitro and in Vivo. Nat. Nanotechnol. 2013, 8, 831-838.

(15) Nasr, K.; Pannier, N.; Frangioni, J. V.; Maison, W. Rigid Multivalent Scaffolds Based on Adamantane. J. Org. Chem. 2008, 73, $1056-1060$.

(16) Montet, X.; Funovics, M.; Montet-Abou, K.; Weissleder, R.; Josephson, L. Multivalent Effects of RGD Peptides Obtained by Nanoparticle Display. J. Med. Chem. 2006, 49, 6087-6093.

(17) Dubacheva, G. V.; Curk, T.; Mognetti, B. M.; Auzély-Velty, R.; Frenkel, D.; Richter, R. P. Superselective Targeting Using Multivalent Polymers. J. Am. Chem. Soc. 2014, 136, 1722-1725.

(18) Ludden, M. J. W.; Reinhoudt, D. N.; Huskens, J. Molecular Printboards: Versatile Platforms for the Creation and Positioning of Supramolecular Assemblies and Materials. Chem. Soc. Rev. 2006, 35, 1122.

(19) Ferrell, J. E., Jr.; Ha, S. H. Ultrasensitivity Part II: Multisite Phosphorylation, Stoichiometric Inhibitors, and Positive Feedback. Trends Biochem. Sci. 2014, 39, 556-569.

(20) Csizmok, V.; Follis, A. V.; Kriwacki, R. W.; Forman-Kay, J. D. Dynamic Protein Interaction Networks and New Structural Paradigms in Signaling. Chem. Rev. 2016, 116, 6424-6462.

(21) Xu, Z.; Jia, S.; Wang, W.; Yuan, Z.; Jan Ravoo, B.; Guo, D.-S. Heteromultivalent Peptide Recognition by Co-Assembly of Cyclodextrin and Calixarene Amphiphiles Enables Inhibition of Amyloid Fibrillation. Nat. Chem. 2019, 11, 86-93.
(22) Albertazzi, L.; Martinez-Veracoechea, F. J.; Leenders, C. M. A.; Voets, I. K.; Frenkel, D.; Meijer, E. W. Spatiotemporal Control and Superselectivity in Supramolecular Polymers Using Multivalency. Proc. Natl. Acad. Sci. U. S. A. 2013, 110, 12203-12208.

(23) Drożdż, W.; Walczak, A.; Bessin, Y.; Gervais, V.; Cao, X.-Y.; Lehn, J.-M.; Ulrich, S.; Stefankiewicz, A. R. Multivalent Metallosupramolecular Assemblies as Effective DNA Binding Agents. Chem. - Eur. J. 2018, 24, 10802-10811.

(24) Awino, J. K.; Gunasekara, R. W.; Zhao, Y. Sequence-Selective Binding of Oligopeptides in Water through Hydrophobic Coding. J. Am. Chem. Soc. 2017, 139, 2188-2191.

(25) van Dun, S.; Ottmann, C.; Milroy, L.-G.; Brunsveld, L. Supramolecular Chemistry Targeting Proteins. J. Am. Chem. Soc. 2017, 139, 13960-13968.

(26) Seeman, N. C.; Sleiman, H. F. DNA Nanotechnology. Nat. Rev. Mater. 2018, 3, 17068.

(27) Dix, A. V.; Moss, S. M.; Phan, K.; Hoppe, T.; Paoletta, S.; Kozma, E.; Gao, Z.-G.; Durell, S. R.; Jacobson, K. A.; Appella, D. H. Programmable Nanoscaffolds That Control Ligand Display to a GProtein-Coupled Receptor in Membranes To Allow Dissection of Multivalent Effects. J. Am. Chem. Soc. 2014, 136, 12296-12303.

(28) Zhang, K.; Deng, R.; Sun, Y.; Zhang, L.; Li, J. Reversible Control of Cell Membrane Receptor Function Using DNA NanoSpring Multivalent Ligands. Chem. Sci. 2017, 8, 7098-7105.

(29) Liu, B.; Huang, Z.; Liu, J. Polyvalent Spherical Nucleic Acids for Universal Display of Functional DNA with Ultrahigh Stability. Angew. Chem., Int. Ed. 2018, 57, 9439-9442.

(30) McLaughlin, C. K.; Hamblin, G. D.; Sleiman, H. F. Supramolecular DNA Assembly. Chem. Soc. Rev. 2011, 40, 5647.

(31) Chidchob, P.; Edwardson, T. G. W.; Serpell, C. J.; Sleiman, H. F. Synergy of Two Assembly Languages in DNA Nanostructures: SelfAssembly of Sequence-Defined Polymers on DNA Cages. J. Am. Chem. Soc. 2016, 138, 4416-4425.

(32) Liu, K.; Zheng, L.; Ma, C.; Göstl, R.; Herrmann, A. DNASurfactant Complexes: Self-Assembly Properties and Applications. Chem. Soc. Rev. 2017, 46, 5147-5172.

(33) Kownacki, M.; Langenegger, S. M.; Liu, S.-X.; Häner, R. Integrating DNA Photonic Wires into Light-Harvesting Supramolecular Polymers. Angew. Chem., Int. Ed. 2019, 58, 751-755.

(34) Engelen, W.; Wijnands, S. P. W.; Merkx, M. Accelerating DNABased Computing on a Supramolecular Polymer. J. Am. Chem. Soc. 2018, 140, 9758-9767.

(35) Alemán García, M. Á.; Magdalena Estirado, E.; Milroy, L.-G.; Brunsveld, L. Dual-Input Regulation and Positional Control in Hybrid Oligonucleotide/Discotic Supramolecular Wires. Angew. Chem., Int. Ed. 2018, 57, 4976-4980.

(36) Wijnands, S. P. W.; Engelen, W.; Lafleur, R. P. M.; Meijer, E. W.; Merkx, M. Controlling Protein Activity by Dynamic Recruitment on a Supramolecular Polymer Platform. Nat. Commun. 2018, 9, 65.

(37) Vyborna, Y.; Vybornyi, M.; Rudnev, A. V.; Häner, R. DNAGrafted Supramolecular Polymers: Helical Ribbon Structures Formed by Self-Assembly of Pyrene-DNA Chimeric Oligomers. Angew. Chem., Int. Ed. 2015, 54, 7934-7938.

(38) Vyborna, Y.; Vybornyi, M.; Häner, R. From Ribbons to Networks: Hierarchical Organization of DNA-Grafted Supramolecular Polymers. J. Am. Chem. Soc. 2015, 137, 14051-14054.

(39) Petkau-Milroy, K.; Sonntag, M. H.; van Onzen, A. H. A. M.; Brunsveld, L. Supramolecular Polymers as Dynamic Multicomponent Cellular Uptake Carriers. J. Am. Chem. Soc. 2012, 134, 8086-8089.

(40) Muller, M. K.; Brunsveld, L. A Supramolecular Polymer as a Self-Assembling Polyvalent Scaffold. Angew. Chem., Int. Ed. 2009, 48, 2921-2924.

(41) van Dun, S.; Schill, J.; Milroy, L.-G.; Brunsveld, L. Mutually Exclusive Cellular Uptake of Combinatorial Supramolecular Copolymers. Chem. - Eur. J. 2018, 24, 16445-16451.

(42) Reynolds, M.; Pérez, S. Thermodynamics and Chemical Characterization of Protein-Carbohydrate Interactions: The Multivalency Issue. C. R. Chim. 2011, 14, 74-95. 
(43) Huskens, J.; Mulder, A.; Auletta, T.; Nijhuis, C. A.; Ludden, M. J. W.; Reinhoudt, D. N. A Model for Describing the Thermodynamics of Multivalent Host-Guest Interactions at Interfaces. J. Am. Chem. Soc. 2004, 126, 6784-6797.

(44) Kitov, P. I.; Bundle, D. R. On the Nature of the Multivalency Effect: A Thermodynamic Model. J. Am. Chem. Soc. 2003, 125 (52), 16271-16284

(45) Motloch, P.; Hunter, C. Thermodynamic Effective Molarities for Supramolecular Complexes. Adv. Phys. Org. Chem. 2016, 50, 77118.

(46) von Krbek, L. K. S.; Schalley, C. A.; Thordarson, P. Assessing Cooperativity in Supramolecular Systems. Chem. Soc. Rev. 2017, 46, $2622-2637$.

(47) Stevers, L. M.; de Vink, P. J.; Ottmann, C.; Huskens, J.; Brunsveld, L. A Thermodynamic Model for Multivalency in 14-3-3 Protein-Protein Interactions. J. Am. Chem. Soc. 2018, 140, 1449814510.

(48) Curk, T.; Dobnikar, J.; Frenkel, D. Design Principles for Super Selectivity Using Multivalent Interactions. In Multivalency; Huskens, J., Prins, L. J., Haag, R., Ravoo, B. J., Eds.; John Wiley \& Sons, Ltd.: Chichester, U.K., 2017; pp 75-101.

(49) Dubacheva, G. V.; Curk, T.; Frenkel, D.; Richter, R. P. Multivalent Recognition at Fluid Surfaces: The Interplay of Receptor Clustering and Superselectivity. J. Am. Chem. Soc. 2019, 141, 25772588. 